\title{
A TEORIA DA FOTOGRAFIA EM WALTER BENJAMIN NA ERA DA SÍNTESE TÉCNICA DE IMAGENS
}

Márcio Seligmann-Silva

\begin{abstract}
"O que torna as primeiras fotografias tão incomparáveis talvez seja isto: elas representam a primeira imagem do encontro entre a máquina e o homem".
\end{abstract}

Walter Benjamin

\section{RESUMO}

O texto apresenta a teoria da fotografia de Walter Benjamin e discute as suas implicações hoje, na era digital. Ele mostra a relação entre a teoria da fotografia e a teoria da memória e da história, em Benjamin e nos dias de hoje.

Palavras-Chave: Fotografia. Teoria da fotografia. Segunda técnica. Fotografia digital. Reprodução técnica.

\section{BENJAMIN'S PHOTOGRAPHY THEORY IN THE ERA OF THE TECHNICAL SYNTHESIS OF IMAGES IMAGENS}

\begin{abstract}
The text presents Benjamin's theory of photography and discuses it's meaning today, in the digital era. It shows the relation between the photography theory and the theory of history and memory, in Benjamin's work and today.
\end{abstract}

Key-words: Photography. Photography theory. Second technic. Digital photography. Technical reproduction 


\section{A fotografia em Walter Benjamin: a "dialética na imobilidade" e a "segunda técnica"}

Estudar o papel da fotografia na obra de Benjamin implica acompanhar sua relação com esse meio que se intensifica sobretudo no contexto de seu trabalho sobre as passagens de Paris. Também é essencial levar em conta que a sua teoria da fotografia está ancorada em sua teoria messiânica da história e em uma original teoria da técnica. No que segue procurarei explorar alguns aspectos dessa rica e elaborada concepção da fotografia, procurando refletir também sobre o significado desses teoremas de Benjamin para nossa era de síntese de imagens e de corpos biológicos.

No seu estudo sobre a fotografia, Benjamin recebeu o impacto de uma série de publicações dos anos 1920 e 1930 que tratavam diretamente da teoria e da história da fotografia. Ele foi impulsionado pela sua amiga Gisele Freund ${ }^{1}$ e por críticos de primeira hora da fotografia, como Louis Figuier (autor de La photographie au salon de 1859, onde ele fala de voyages photographiques (BENJAMIN, 2006, 724). Se Freund marca Benjamin com a ideia de que com a fotografia toda a concepção de arte se modificou e que a fotografia é elevada ao nível da arte na mesma medida em que ela se torna uma mercadoria, o conceito de voyages photographiques também impressionou Benjamin e foi ao encontro de sua teoria que estabelece uma relação entre o nascimento das massas e o da fotografia: ambas seriam marcadas por uma pulsão de aproximar tudo. Desse modo, a fotografia, para Benjamin, aproxima as paisagens, monumentos e os países mais distantes, assim como as obras de arte, que antes apenas o viajante podia ver ao visitar os museus. Já no volume Entretiens, L'art et la réalité. L'art et l'état (Paris: Institut internationale de coopération intelectuelle, 1935) ele pôde ler ideias de Lhote como a que afirma que "cada nova técnica [...] baseia-se em uma nova ótica" ${ }^{2}$, tese que ele desenvolve em seus escritos sobre a fotografia e o cinema.

\footnotetext{
${ }^{1}$ Autora de La Photographie en France au dix-neuvième siècle. Essai de sociologie et d'esthétique, Paris: La Maison des amis du livre, 1936.

2 Benjamin, 1972: 499; "Pariser Brief 2, Malerei und Photographie".

Professor titular de Teoria Literária do Instituto de Estudos da Linguagem, IEL da Universidade Estadual de Campinas, UNICAMP. Brasileiro, residente em Campinas - SP. Email: $\underline{\text { m.seligmann@uol.com.br }}$
} 
A teoria da fotografia de Benjamin pode ser lida tanto nas resenhas de exposições fotográficas e de livros, como o de Freund, como também em sua "Pequena história da fotografia", de 1931, nas suas "Cartas de Paris 2, Pintura e fotografia", de 1936, e sobretudo em seu conhecido texto sobre a obra de arte na era de sua reprodutibilidade técnica, de 1936. Além disso, sua teoria das imagens dialéticas e da dialética paralisada, ou seja, a sua teoria da história, deve ser interpretada no sentido forte de uma teoria das imagens que, como tentarei mostrar, pode ser posta em curto circuito com a sua teoria das imagens técnicas.

Temos que lembrar que Benjamin via em seu estudo sobre a obra de arte uma resposta aos terríveis fatos políticos de que era contemporâneo: a ascensão do nazi-fascismo, os desdobramentos da sociedade capitalista com suas crises e a guerra iminente. Seu ensaio sobre a obra de arte deve ser entendido também como uma parte fundamental do grande projeto sobre as passagens de Paris que ele levou a cabo - com algumas interrupções desde 1927 até a sua morte. Esse projeto visava uma espécie de elaboração do século XIX, um despertar de suas fantasmagorias. Como parte desse projeto, cabia estudar os novos meios de composição, reprodução e divulgação das artes, onde os avanços da técnica se faziam perceber de modo claro. Como é conhecido, em Benjamin, o estudo da estética confundia-se com uma análise social e uma crítica da cultura. Em um fragmento sobre esse ensaio, Benjamin anotou algo que indica essa pertença ao projeto das passagens: "O trabalho não vê de modo algum que a sua tarefa consiste em fornecer os prolegômenos para uma história da arte. Antes, ele se dedica em primeiro lugar a abrir o caminho para uma crítica do conceito de arte que nos chegou do século XIX." (BENJAMIN, 1974, 1050) Esse conceito de arte herdado do século XIX seria místico, mágico e abstrato, eivado de um caráter enganoso e "ideológico", como escreve Benjamin no mesmo fragmento. Ele estava preocupado em estudar os novos regimes de visualidade e de percepção do mundo, diretamente determinados pelas aceleradas mudanças técnicas, já que, para ele, o homem moderno não poderia ser compreendido sem essa análise da técnica. Como vimos, a técnica para ele determina novos modos de percepção. Se para Alexander 
Gottlieb Baumgarten, em meados do século XVIII, a teoria da percepção (aisthesis em grego) poderia ser elaborada de modo muito mais profícuo a partir do estudo da recepção de obras de arte (concepção esta que está na origem da teoria estética moderna), para Benjamin, na primeira metade do século $\mathrm{XX}$, com o triunfo das grandes cidades, do fotojornalismo, das vanguardas, da fotografia artística, do cinema e do rádio, uma reflexão crítica sobre a sociedade moderna dependia de uma teoria da técnica e de sua aplicação nas artes. Se em Baumgarten as artes eram uma porta para o estudo da nossa percepção do mundo, em Benjamin as artes são vistas como uma caixa de ressonância privilegiada para a compreensão do novo papel da técnica. Sem perder de vista que a arte tem muito a ver com a percepção, Benjamin nunca se esquece também da concepção grega das artes como tékhné. A técnica, como vemos no mito prometeico, é sempre uma tentativa, ambígua, de "restituir" ao ser humano uma totalidade. A teoria da percepção e a teoria estética são reelaboradas por Benjamin a partir de uma filosofia da arte que traz em seu âmago mesmo o conceito de técnica. Tendo a técnica agora um lugar tão privilegiado na teoria estética, essa última passa a ser pensada intensamente do ponto de vista de uma teoria social. Como o primeiro e o último capítulo do ensaio de Benjamin sobre a obra de arte deixam claro, para esse autor não se pode pensar as artes e a estética sem se levar em conta a política.

No contexto do projeto sobre as passagens, que justamente emprestava como título o nome dessas formações técnico-arquitetônicas em ferro do século XIX, as passagens comerciais, Benjamin já fizera várias incursões sobre temas afins ao seu trabalho sobre a obra de arte. Mas já antes desse projeto, em 1924, ele publicara na revista $G$ uma tradução do ensaio de Tristan Tzara - o poeta romeno que participou da fundação do movimento dadaísta de Zurique em 1916 - sobre as fotografias sem câmara de Man Ray. As ideias de Benjamin sobre as artes só podem ser compreendidas no contexto das vanguardas. No referido artigo "Pequena história da fotografia", de 1931, Benjamin já se mostra como parte do circulo de teóricos e especialistas em imagens técnicas, que englobava também Lázló Moholy-Nagy, grande professor da Bauhaus, teórico e prático da

Professor titular de Teoria Literária do Instituto de Estudos da Linguagem, IEL da Universidade Estadual de Campinas, UNICAMP. Brasileiro, residente em Campinas - SP. 
fotografia sem câmera. ${ }^{3}$ Infelizmente a recepção do ensaio de Benjamin sobre a obra de arte muitas vezes o retira desse interessante contexto do debate vanguardista sobre a arte, no qual, sobretudo nos anos 1920 e 1930, imperava um otimismo com relação ao potencial revolucionário das artes. Moholy-Nagy em ensaios como "Produção - reprodução" (publicado em 1922 na revista De Stijl) ou em seu texto "Fotograma", de 1926, já apresentava algumas das ideias que depois Benjamin desenvolveria, embora, é verdade, a seu modo. Por exemplo, Moholy-Nagy discutia a fotografia como um meio que não apenas se afirmava a partir da reprodução, mas que também tinha uma performance produtiva. ${ }^{4}$

Outra importante referência que influenciou de modo decisivo a visão de arte de Benjamin foi o seu amigo e jornalista Siegfried Kracauer. Seu

\footnotetext{
${ }^{3}$ Moholy-Nagy publicou em 1927 uma obra fundamental nesse contexto, que era conhecida por Benjamin: Malerei, Photographie, Film (Pintura, fotografia, filme). Nessa época são publicados também muitos livros de fotografia, com obras de Eugène Atget (Man Ray e os demais membros do surrealismo veneravam sua obra, que também é analisada por Benjamin no seu ensaio sobre a obra de arte), August Sander (o maior fotógrafo retratista alemão, que publicou em 1929 seu Antlitz der Zeit [Rosto da época]), Karl Blossfeld (o famoso fotógrafo de closes da natureza, cuja exposição de 1926 foi resenhada pelo próprio Benjamin) e Albert Renger-Patzsch (um fotógrafo que trabalhou na publicidade e na indústria e foi um dos fundadores da Nova Objetividade. Seu livro Die Welt ist schön [O mundo é belo], é marcado por fotos que acentuam o aspecto repetitivo do mundo tecnológico e massificado moderno. Benjamin critica essa obra em suas cartas de Paris, por sucumbir ao culto burguês do belo. BENJAMIN, 1972, 504s.).

${ }^{4}$ Várias formulações de Moholy-Nagy antecipam teoremas de Benjamin. Cito dois exemplos: "a fotografia possui a sua justificativa não apenas enquanto técnica reprodutiva, pois ela já levou a realizações produtivas." (Moholy-Nagy, 1991: 154.) Já no artigo sobre fotograma (fotografias sem câmera, obtidas com a exposição à luz do papel fotográfico sobreposto por objetos), ele nota que os fotogramas de Man Ray tinham por objetivo "compreender o enigmático, sinistro [Unheimlich], não-cotidiano do cotidiano, criar uma aura para o habitual, trazer à consciência o invisível (metafísico, oculto) daquilo que parecia desapercebido." (MOHOLY-NAGY, 1991, 155.) Vemos aqui a tese do inconsciente ótico, de que Benjamin trata em seu ensaio sobre a obra de arte, mas a visão de aura defendida aqui por MoholyNagy é bem distinta da de Benjamin, que quase sempre a opõe à reprodutibilidade técnica. De A. Huxley, Benjamin copiou em suas notas uma passagem de um artigo (também citado por ele na terceira versão de seu ensaio sobre a obra de arte) na qual Huxley trata dos efeitos qualitativos que a reprodução tem para as artes: "'Com cópias na ordem de milhões', escreveu Huxley, 'também o objeto o mais belo torna-se feio."' (BENJAMIN, 1974, 1050.) Essa ideia, apesar de Benjamin não aplicar o conceito de "feio", é fundamental para o seu argumento. Benjamin deriva da crise instaurada na aura por conta da reprodutibilidade técnica uma crise na visão da arte como imitação e reprodução do belo. (BENJAMIN, 1989, 139) Se as obras de arte nunca poderiam ser totalmente esgotadas e traduzidas em seu enxame de sensações e ideias que desencadeiam, a fotografia seria uma espécie de alimento que estanca o desejo que projetamos nas obras de arte auráticas: "O que separa a fotografia da pintura, e o motivo de não haver um princípio único e extensível de criação para ambas, está claro, portanto: para o olhar que não consegue se saciar ao ver uma pintura, uma fotografia significa, antes, o mesmo que o alimento para a fome ou a bebida para a sede." (Benjamin, 1989, 128)

Professor titular de Teoria Literária do Instituto de Estudos da Linguagem, IEL da

Universidade Estadual de Campinas, UNICAMP. Brasileiro, residente em Campinas - SP. Email: $\underline{\text { m.seligmann@uol.com.br }}$
} 
ensaio "O ornamento da massa", de 1927, ou ainda, o seu "O culto da dispersão [Zerstreuung]", do ano anterior, realizam uma análise da moderna "cultura do corpo" e das "fábricas americanas de dispersão" que adiantam os estudos benjaminianos sobre a arte moderna, nos quais a associava a uma recepção dispersa e distraída (apesar de em Benjamin não percebermos mais o tom condenatório de Kracauer). Como Kracauer ainda nota, essa massa organizada é a mesma que vem das fábricas e escritórios. O elemento eminentemente ótico do modo de pensar e escrever de Kracauer, que também nesse ponto o unia a Benjamin, fica evidente nos textos de descrição e reflexão sobre a cidade, nos quais vemos como é possível se filosofar a partir do gesto do flâneur. As suas "Observações de Paris" ("Pariser Beobachtungen"), de 1926, marcaram definitivamente os Diários de Moscou de Benjamin, escritos no ano seguinte. Também outro trabalho de Kracauer, a saber, seu ensaio sobre a fotografia, de 1927, veio a influenciar Benjamin (inclusive a sua teoria da publicidade). Nele lemos uma descrição da sociedade que se protege de si mesma - e da morte - por meio de uma avalanche de imagens.

As tentativas de opor, na teoria das artes, a reprodução à produção era na verdade uma tema clássico. Desde a Antiguidade e, com mais ímpeto, a partir do Renascimento e até o século XVIII, discutia-se muito se as obras e os artistas deveriam imitar e reproduzir a natureza e as obras de arte "clássicas", ou, por outro lado, se deveriam buscar uma obra distinta, ela mesma digna de ser imitada. Na antiguidade o culto da originalidade já se manifesta no tratado anônimo Sobre o sublime. Sob o signo da assim chamada "querela dos antigos e dos modernos", esse tema foi debatido a partir do século XVII, por autores como Charles Perrault e Johann Joachim Winckelmann. Discutia-se a capacidade dos modernos conseguirem se tornar eles mesmos melhores ou ao menos dignos de serem copiados. Winckelmann fornece, no seu texto programaticamente denominado de Gedanken über die Nachahmung der griechischen Werke in der Malerei und Bildhauerkunst (Reflexões sobre a imitação das obras gregas na pintura e na escultura), de 1755, a formulação que se tornou emblemática nesse debate: 
"O único meio de nos tornarmos grandes e, se possível, inimitáveis é imitar os antigos" (WINCKELMANN, 1995, 14).

Com a técnica fotográfica, no entanto, a arte como reprodução passou a ser pensada, com Benjamin, de um modo inteiramente diverso, não mais enquanto re-produção de um objeto ou tema, mas sim enquanto produção da própria obra. Para ele, o fundamental é que a fotografia é intrinsecamente reprodutível. Isso implicou um abalo na tradição, um rompimento com ela, lançando, portanto, a modernidade em um outro paradigma, onde o que conta não é mais imitar (a natureza ou os grandes modelos) ou ser original, mas sim o fato de não existir mais uma identidade única, fechada, da obra, do seu produtor e daquilo que eventualmente ela venha a representar.

Detlev Schöttker, comentando as possíveis influências que atuaram sobre o conceito de reprodução de Benjamin, recorda que na revista Literarische Welt (Mundo literário), para a qual Benjamin contribuía regularmente, foi publicado em 31 de julho de 1931 (no mesmo número em que apareceu o pequeno texto de Benjamin "Desempacotando a minha biblioteca") um debate entre o editor Willy Haas e o pintor Fritz Pollak. Enquanto este último condenava as reproduções, o outro as defendia. Haas sustentava a opinião segundo a qual na nossa era o conceito de "original" perdeu seu sentido social. Nos termos de sua "função social", para Haas as reproduções seriam mais originais do que os originais que estão nos museus. (BENJAMIN, 2006, 116) Esse ponto de vista de Haas não deixa de lembrar, por outro lado, um debate de mais de cem anos antes, levado a cabo pelos românticos de lena, bem conhecidos de Benjamin, quando esses autores (sobretudo os irmãos Schlegel e Novalis) defendiam uma reversão crítica da ideia de original em favor das cópias. Essa concepção se desenvolveu sobretudo no contexto da teoria romântica da tradução. August W. Schlegel defendia uma valorização desconstrutora do que normalmente é visto como sendo secundário. No fragmento 110 da revista Athenäum ele anotou: "É um gosto sublime sempre preferir as coisas à segunda potência. Por exemplo, cópias de imitações [Kopien von Nachahmungen], julgamentos de resenhas, adendos à acréscimos, comentários a notas." Ao invés dos românticos de lena trabalharem de modo rígido com a ideia de fidelidade, submetida ao 
paradigma tradicional da representação, eles preferiam pensar a partir de conceitos como o de oscilar (Schweben), ironia, parábase, autorreflexão, desdobramento, dissimulação (Verstellung), alegoria e mesmo de tradução, como operadores para se pensar toda a cultura. Não podemos deixar de lado esse universo de ideias ao tratar das teses defendidas por Benjamin em 1936 sobre a reprodução como superação da tradição.

No segundo capítulo do seu ensaio sobre a obra de arte, Benjamin apresenta uma de suas teses centrais: "Por volta de 1900 a reprodução técnica tinha atingido um padrão que Ihe permitiu não somente tornar a totalidade das obras de arte convencionais em seu objeto, submetendo seus efeitos às mais profundas modificações, mas também conquistar um lugar próprio entre os procedimentos artísticos." (BENJAMIN, 2013, 53 ; BENJAMIN 1989a, 351s.) Lendo essa passagem com os olhos dos habitantes do século XXI, a tentação não é pequena (e creio que devemos ceder a ela) de substituir a data de 1900 pela de 2000 - substituindo também, é claro, as mídia em questão: ao invés da fotografia e do cinema, hoje falamos da computação e do universo da web. Também esses dois novos fenômenos permitem uma "repaginação" de toda história da arte (eles incorporam tudo e resignificam a tradição e seu status). Além disso, devemos considerar a arte computacional e a web como fenômenos estéticos em si que incidem sobre a história da arte e da técnica, bem como sobre nossos conceitos de arte e de literatura. Sem dúvida, é por reflexões como essa que o ensaio de Benjamin sobre a obra de arte continua absolutamente atual. Ele nos ensina a ler a história do ponto de vista da técnica e de sua determinação sobre nosso modo de ver e perceber o mundo.

Pouco antes dessa passagem citada, Benjamin formulara o seguinte sobre os novos aparatos de captação do mundo: "Como o olho apreende mais rápido do que a mão desenha, o processo de reprodução figurativa foi acelerado de modo tão intenso que agora ele podia acompanhar o ritmo da fala." (BENJAMIN, 2013, 53; BENJAMIN, 1989a, 351) Nesse passo Benjamin não está fazendo outra coisa que não atualizar para sua época uma teoria das mídia, tal como Lessing, em 1766, em seu Laocoonte, havia feito, segundo os padrões de sua época. Lessing tentara pensar a especificidade

Professor titular de Teoria Literária do Instituto de Estudos da Linguagem, IEL da Universidade Estadual de Campinas, UNICAMP. Brasileiro, residente em Campinas - SP. 
de cada arte e, para tanto, teve que fazer uma reflexão sobre a relação de cada modalidade artística com os sentidos de nosso aparelho perceptório. No capítulo XVI de seu clássico e central ensaio sobre as artes, Lessing resumiu:

\begin{abstract}
Se é verdade que a pintura utiliza nas suas imitações um meio ou signos totalmente diferentes dos da poesia; aquela, a saber, figuras e cores no espaço, já essa sons articulados no tempo; se indubitavelmente os signos devem ter uma relação conveniente com o significado: então signos ordenados um ao lado do outro também só podem expressar objetos que existam um ao lado do outro, ou cujas partes existem uma ao lado da outra, mas signos que se seguem um ao outro só podem expressar objetos que se seguem um ao outro ou cujas partes se seguem uma a outra.

Objetos que existem um ao lado do outro ou cujas partes existem uma ao lado da outra chamam-se corpos. Consequentemente são os corpos com as suas qualidades visíveis que constituem o objeto próprio da pintura.

Objetos que se seguem um ao outro ou cujas partes se seguem uma a outra chamam-se em geral ações. Consequentemente as ações constituem o objeto próprio da poesia. (LESSING, 2011, 195)
\end{abstract}

Benjamin estabelece uma nova reflexão acerca dessa relação entre as artes e o corpo para o homem do século XX. Desse modo, ele nos apresenta como proceder para (nos) pensarmos diante da revolução midiática que nos é contemporânea. A situação de abalo da tradição que ele descreve só fez se agravar com o tempo, nos cerca de 75 anos que nos separam de seu ensaio. Assim, Benjamin tece, no capítulo III do ensaio sobre a obra de arte, uma relação entre a reprodução técnica e a superação do elemento único da obra. Diante da obra/reprodução não cabe mais falar de sua autenticidade. "A autenticidade de uma coisa é a quintessência de tudo que nela é originalmente transmissível, desde sua duração material até 0 seu testemunho histórico. Como este testemunho está fundado sobre a duração material, no caso da reprodução, onde esta última tornou-se inacessível ao homem, também o primeiro - o testemunho histórico da coisa - torna-se instável." (BENJAMIN, 2013, 55; BENJAMIN, 1989a, 353) A era da reprodutibilidade nos joga abruptamente no tempo após a era do testemunho histórico. Talvez seja por conta desse mesmo fato que, podemos pensar hoje, tanto se falou e fala no testemunho. O século $X X$, como um século de catástrofes, guerras e genocídios, exigiu o testemunho, mas também revelou seus limites. Paradoxalmente, nas últimas duas décadas é a fotografia

Professor titular de Teoria Literária do Instituto de Estudos da Linguagem, IEL da Universidade Estadual de Campinas, UNICAMP. Brasileiro, residente em Campinas - SP. Email: $\underline{\text { m.seligmann@uol.com.br }}$ 
analógica que tem servido como um dos modelos do testemunho histórico: pois de um modo geral temos a impressão de que a era digital, com mais razão ainda do que a da fotografia e do filme analógicos, bloqueia qualquer relação com o evento inscrito na escrita eletrônica dos pixels. Mas vale a pena retomar o texto de Benjamin nesse ponto: ele nos mostra como a era das imagens reproduzidas e reprodutíveis já traz em si essa ideia de abalo do "testemunho histórico", geschichtliche Zeugenschaft. Temos de lembrar que zeugen, de onde deriva testemunhar em alemão, remete a gerar, procriar, reproduzir, ser pai. Se entramos, com a reprodução técnica, em uma era sem reprodução no sentido de gerar, é também porque geramos sem a fecundação, ao produzirmos robôs ou clones. Para Benjamin, o "abalo da tradição", provocado pela reprodução técnica, não é nada senão "o outro lado da crise e da renovação atuais da humanidade". E essa crise, creio, não deixou de se aprofundar. Não por acaso a sociedade pós geração natural de seres humanos se tornou um topos na ficção científica - já desde a novela fundadora do gênero de Mary Shelley, Frankenstein, ou o moderno Prometeu.

Mas a arqueologia dessa crise é feita por Benjamin antes de mais nada em seus estudos sobre Baudelaire. Em Baudelaire, Benjamin pôde perceber, para além do crítico da fotografia que via nela uma proximidade das massas (aspecto que Benjamin julgava positivo), alguém que notou sua tendência a se aproximar da ciência, ideia muito cara a Benjamin, que via na fotografia uma espécie de triunfo do aspecto técnico da obra de arte. Baudelaire anotou no seu "O público moderno e a fotografia":

A poesia e o progresso são dois ambiciosos que se odeiam de um ódio instintivo, e quando se encontram no mesmo caminho, é necessário que um sirva ao outro. Se for permitido à fotografia substituir a arte em qualquer uma de suas funções, ela logo será totalmente suplantada e corrompida, graças à aliança natural que encontrará na tolice da multidão. É preciso então que ela retorne ao seu verdadeiro dever, que é o de ser a serva das ciências e das artes, a mais humilde das servas, como a imprensa e a estenografia, que nem criaram e nem suplantaram a literatura. Que ela enriqueça rapidamente o álbum do viajante e devolva a seus olhos a precisão que faltava a sua memória, que ela ornamente a biblioteca do naturalista, amplie os animais microscópicos, ou mesmo, que ela acrescente ensinamentos às hipóteses do astrônomo, que ela seja enfim a secretária e o guarda-notas de

Professor titular de Teoria Literária do Instituto de Estudos da Linguagem, IEL da Universidade Estadual de Campinas, UNICAMP. Brasileiro, residente em Campinas - SP. 
quem quer que precise, em sua profissão, de uma absoluta precisão material, até aí, nada melhor.

Essa passagem continua de modo surpreendente, pois Baudelaire acaba atribuindo à fotografia qualidades que vão claramente para além do campo científico. Ele vai falar tanto de suas qualidades de arquivo, como de salvação, em imagem, daquilo que vai se transformar em ruinas. Essa ideia também era cara a Benjamin. Continuemos a passagem de Baudelaire:

\begin{abstract}
Que ela salve do esquecimento as ruínas decadentes, os livros, as estampas e os manuscritos que o tempo devora, as coisas preciosas cuja forma irá desaparecer e que pedem um lugar no arquivo de nossa memória, ela terá nossa gratidão e será ovacionada. ${ }^{5}$ (BAUDELAIRE, apud ENTLER, 2007, 10)
\end{abstract}

Não podemos esquecer que Baudelaire era um idólatra das imagens. A multiplicação quantitativa de imagens de que ele foi contemporâneo, pode ser explicada não só pela facilidade técnica, mas também por uma necessidade quase que patológica do indivíduo contemporâneo de registrar tudo em imagens. "Glorifier le culte des images (ma grande, mon unique, ma primitive passion)", escreveu Baudelaire. Estas palavras caracterizam também o indivíduo contemporâneo com sua sede de construir uma casa em um mundo onde tudo se liquefaz. Como suas imagens também são líquidas, ele não para de inscrevê-las. Nossa era de museus e arquivos é uma filha de nosso descolamento da tradição e, mais recentemente, de nossa crise quanto aos limites do próprio humano. Se Benjamin constatou que aquilo que está para desaparecer assume a forma de uma imagem, nas fotografias das ruas de Paris de Atget reconhecemos uma total consciência deste fato. No verso das suas fotografias o fotógrafo anotava: "Va disparaître".

A partir de Baudelaire e de sua lírica que incorpora o choque da vida moderna, Benjamin desenvolve, com recurso a Bergson, Proust e Freud, uma teoria da onipresença dos choques. Ele considera o gesto da captação da fotografia como parte de uma série de novos pequenos gestos que se

\footnotetext{
${ }^{5}$ Benjamin alude a essa passagem em "Sobre alguns temas em Baudelaire": "[Para Baudelaire] A fotografia pode se apoderar, sem ser molestada, das coisas transitórias, que têm o direito 'a um lugar nos arquivos de nossa memória', desde que se detenha ante os 'domínios do abstrato, do imaginário'”. (BENJAMIN, 1989, 138)

Professor titular de Teoria Literária do Instituto de Estudos da Linguagem, IEL da Universidade Estadual de Campinas, UNICAMP. Brasileiro, residente em Campinas - SP. Email: $\underline{\text { m.seligmann@uol.com.br }}$
} 
associam a mudanças complexas, como o de riscar o fósforo (invenção que ele considera paradigmática).

Entre os inúmeros gestos de comutar, inserir, acionar etc., especialmente 0 'click' do fotógrafo trouxe consigo muitas consequências. Uma pressão do dedo bastava para fixar um acontecimento por tempo ilimitado. $\mathrm{O}$ aparelho como que aplicava ao instante um choque póstumo. Paralelamente às experiências ópticas desta espécie, surgiam outras táteis, como as ocasionadas pela folha de anúncio dos jornais, e mesmo pela circulação na cidade grande. O mover-se através do tráfego implicava uma série de choques e colisões para cada indivíduo." (BENJAMIN, 1989, 124)

Benjamin também destaca o papel da fotografia como técnica de fixar a identidade do indivíduo moderno, que vive em um mundo onde cada vez se sente menos em casa, onde ele não reconhece as marcas de sua existência. Essas marcas, agora são vistas como vestígios no sentido jurídico das marcas de um crime. A sociedade na qual o choque impera, é também aquela na qual o indivíduo está submetido a uma nova cadeia de controles. A fotografia contribuiu de modo fundamental para essa nova situação:

Nos primórdios dos procedimentos de identificação, cujo padrão da
época é dado pelo método de Bertillon, encontramos a definição da
pessoa através da assinatura. Na história desse processo, a
descoberta da fotografia representa um corte. Para a criminalística
não significa menos que a invenção da imprensa para a literatura.
Pela primeira vez, a fotografia permite registrar vestígios
duradouros e inequívocos de um ser humano. (BENJAMIN, 1989, 45)

Mas contra um lado seu que podemos chamar de melancólico, Benjamin comemora no choque a possibilidade de uma refundação da cultura. Ele saúda a nova barbárie. A sua teoria do choque não só apresenta um sujeito que não é mais dono de si e que vive, como escrevia Freud, no Unbegehagen in der Kultur (Mal-estar na cultura), ou seja, no desabrigo da cultura, na ausência de casa, como também anuncia a era nova de um pensamento pós dualismos. Benjamin como que previu aquilo que Primo Levi descreveu como sendo a zona cinzenta. Como Kafka, antes de Auschwitz, Benjamin também nos fornece elementos para o que resta da filosofia após aquele evento. Trata-se da pós-metafísica. O projeto de Benjamin não era o de simplesmente criticar condenando a onipresença dos choques, mas de

Professor titular de Teoria Literária do Instituto de Estudos da Linguagem, IEL da Universidade Estadual de Campinas, UNICAMP. Brasileiro, residente em Campinas - SP. Email: m.seligmann@uol.com.br 
desviar a carga desses choques no sentido de um aproveitamento revolucionário deles. Ele, nesse gesto, uniu-se às vanguardas. Mas ele percebe também que, nesse sentido, a forma acabada da proposta das vanguardas se dá por meio dos novos aparelhos técnicos: a fotografia e, sobretudo, o cinema. Contra o Futurismo de Marinetti e seu culto da técnica como máquina de guerra, Benjamin desenvolve uma teoria de uma segunda técnica, que se oporia a essa técnica destruidora.

O cinema e a fotografia estariam entre as concretizações mais evidentes dessa segunda técnica. Eles também incorporam o choque em seus procedimentos. A fotografia com o tiro ou olhar de Medusa que congela o tempo e o conecta a outros aqui e agora, e o cinema, com seus cortes e a montagem que potencializa a sua capacidade de penetrar e revelar o real. $O$ choque, lembra Benjamin, a partir do Freud de Para além do princípio do prazer, rompe o Reizschutz, nossa carapaça psíquica que nos envolve, e revela o indivíduo como um corpo frágil. Por outro lado, o indivíduo moderno precisa estar adestrado para enfrentar esses choques. Benjamin vê no cinema um tal meio de educação. Ele também incorpora o princípio do teste: os atores são testados para serem contratados e, além disso, a performance do ator diante da máquina ensina seu público a enfrentar, no trabalho, a máquina que suga a sua humanidade. A fotografia e o cinema são vistos por Benjamin como dois dispositivos que nos ensinam a impedir a revolta prometeica da técnica. Neles, ao invés da técnica nos dominar, ela serve para uma reconquista não violenta da natureza.

Na sociedade pós-aurática o seu habitante está sendo posto a prova todo tempo, ele está submetido ao perigo, e é por meio desse estar em perigo radical que ele faz a sua "experiência". "Articular o passado historicamente não significa reconhecê-lo 'como ele de fato aconteceu'. Significa apropriar-se de uma recordação como ela relampeja no momento do perigo" (BENJAMIN, 1974, 695), anotou Benjamin no contexto de suas teses sobre a filosofia da história, e ainda: "A imagem é aquilo em que o ocorrido encontra o agora num lampejo, formando uma constelação. Em outras palavras: a imagem é a dialética na imobilidade. Pois, enquanto a relação do presente com o passado é puramente temporal, a do ocorrido com o agora é

Professor titular de Teoria Literária do Instituto de Estudos da Linguagem, IEL da Universidade Estadual de Campinas, UNICAMP. Brasileiro, residente em Campinas - SP. 
dialética - não de natureza temporal, mas imagética. [...] A imagem lida, quer dizer, a imagem no agora da cognoscibilidade, carrega no mais alto grau a marca do momento crítico, perigoso, subjacente a toda leitura". (BENJAMIN, 2006, 505; BENJAMIN, 1982, 578) O perigo é também o de cair no esquecimento, assim como 0 de se manter não lida e encoberta pela narrativa tradicional - épica, linear - que apresenta na visão benjaminiana apenas o triunfo dos vencedores. $\mathrm{Na}$ imagem ao invés do narrado encontramos uma densificação do histórico que o arranca do fluxo da dominação. O crítico cultural materialista agarra o ocorrido e o mergulha no agora, como um fotógrafo que rapta um aqui e agora e o arrasta para outros cronotopoi. Não se trata mais de apanhar e reproduzir a tradição, isso era o registro a que a cultura se submeteu na era que Benjamin denomina de aurática, ou seja, na qual domina a recepção distante e respeitosa da obra de arte, vista como portadora de uma tradição. Benjamin faz uma teoria da nova experiência, ou da experiência possível, na era da onipresença dos choques, pós-tradicional. Sua teoria da história e antropologia do novo habitante da era moderna é imagética e possui amplas ramificações com sua filosofia e teoria das imagens técnicas. O momento do saber deve ser pensado sob o signo da ação transformadora, da construção da imagem e de sua leitura libertadora. Trata-se de transformar os choques em um dínamo da mudança social efetiva. A imagem é dialética na imobilidade, local de encontro do conceito com a imagem, de tradução de uma na outra. A imagem deixa de ser vista como memória encobridora, como sugeria Kracauer escrevendo sobre a fotografia, e se torna medium-de-reflexão.

Para Benjamin - dentro de uma visão muito cara à psicanálise nossa língua é sobrevivente da catástrofe e é a única que porta tanto o ocorrido, como a possibilidade de trazê-lo para o nosso agora. Essa atualização, para ele, é ela mesma violenta. "A intervenção [Zugriff] segura, aparentemente brutal pertence à imagem da 'salvação'" (BENJAMIN, 1974, 677). Essa salvação é o corte no continuum da história que é visto como a continuidade da opressão (BENJAMIN, 1974, 1244). Nada mais revelador tanto para a história da humanidade, como para a de cada indivíduo. Ele também anotou de modo eloquente na mesma direção: "Marx afirma que as

Professor titular de Teoria Literária do Instituto de Estudos da Linguagem, IEL da Universidade Estadual de Campinas, UNICAMP. Brasileiro, residente em Campinas - SP. 
revoluções são as locomotivas da história do mundo. Mas talvez isso seja totalmente diferente. Talvez as revoluções sejam o freio de emergência da humanidade que viaja neste trem" (BENJAMIN, 1974, 1232). A essa interrupção da história corresponde o gesto do historiador/alegorista que também congela o passado em imagens. O conceito benjaminiano de imagem dialética é o resultado dessa concepção da historiografia como destruição da "falsa aparência da totalidade", ou seja de nossas narrativas e imagens encobridoras:

Pertencem ao pensamento tanto a paralisação [Stillstellen] quanto o movimento dos pensamentos. Onde o pensamento paralisa-se numa constelação carregada de tensões aí aparece a imagem dialética. Ela é a cesura no movimento do pensamento [Es ist die Zäsur in der Denkbewegung]. Naturalmente o seu local não é arbitrário. Ela deve ser procurada, com uma palavra, onde a tensão entre os opostos dialéticos encontra-se no máximo. Assim, a imagem dialética é o objeto mesmo construído na exposição histórica materialista. Ela é idêntica ao objeto histórico; ela justifica o seu arrancar para fora do continuum do percurso da história (BENJAMIN, 1982, 595).

Assim como para o alegorista o mundo desvencilhado de todo significado ontologicamente determinado transformava-se num conjunto de imagens que deveriam ser reinvestidas de sentido, do mesmo modo o historiador/colecionador vê a história desmoronar em imagens carregadas de tensões: ele as desperta a partir do seu agora (BENJAMIN, 1982, 578). É dispensável, creio, enfatizar o paralelo possível de ser feito aqui com a situação do tête-à-tête na clínica psicanalista. Sem contar que as imagens dialéticas são definidas ainda por Benjamin como "a memória involuntária da humanidade redimida" (BENJAMIN, 1982, 1233). Ou seja, o agora que está na base do conhecimento da história estrutura, para Benjamin, o reconhecimento de uma imagem do passado que, na verdade, é uma "imagem da memória. Ela aparenta-se às imagens do próprio passado que surgem diante das pessoas no momento de perigo" (BENJAMIN, 1974, 1243). Ao invés da busca da representação (mimética) do passado "tal como ele foi", como as posturas tradicionais historicistas e positivistas (em uma palavra: representacionistas) da história o postulavam, Benjamin quer articular o passado historicamente apropriando-se "de uma reminiscência". O historiador deve ter presença de espírito (Geistesgegenwart) para apanhar

Professor titular de Teoria Literária do Instituto de Estudos da Linguagem, IEL da Universidade Estadual de Campinas, UNICAMP. Brasileiro, residente em Campinas - SP. 
essas imagens nos momentos que elas se oferecem: assim ele pode salválas, paralisando-as (BENJAMIN, 1974, 1244): como um fotógrafo do tempo. Essa história construída com base na memória involuntária despreza e liquida o "momento épico da exposição da história", ou seja, a sua representação segundo uma narração ordenada monologicamente. "A memória involuntária nunca oferece [...] um percurso mas sim uma imagem. (Daí a 'desordem' como o espaço-imagético da memória involuntária.)" (BENJAMIN, 1974, 1243). Essa imagem é lida pelo historiador (psicanalista da história) e portanto, é uma imagem hieroglífica: misto de palavra e imagem.

Benjamin nos seus textos dos anos trinta, deixa claro que, para ele, a tarefa do crítico era liberar o que eu denominaria de teor escritural - ou seja, catastrófico - do "real". Mais do que nunca, em uma época trágica como a vivida por Benjamin, essa essência traumática do "real" torna-se palpável e, como em Freud, a sua teoria do conhecimento é toda derivada da vivência do choque que marca a modernidade e sobretudo esse período de sua dissolução. As suas análises críticas da sociedade se desdobram na sua teoria das novas mídias, tais como o cinema e a fotografia. Os aparelhos dessas novas mídias são vistos a um só tempo como potenciais libertadores — do peso da tradição e do passado - e como agentes de destruição. Eles incorporam o princípio do choque para aplicá-lo de volta ao "real". Se em Freud - como ocorre em seu texto sobre o boco mágico - a metáfora fotográfica é uma constante para apresentar a nossa psique como um aparelho mnemônico que registra traços da realidade, também o psiquiatra Ernst Simmel, autor de Kriegsneurosen und psychisches Trauma (Neuroses de guerra e o trauma psíquico, 1918), descreveu o trauma de guerra com uma fórmula que deixa clara a relação entre técnica, trauma, violência e o registro de imagens: "A luz do flash do terror cunha/estampa uma impressão/cópia fotograficamente exata" ("Das Blitzlicht des Schreckens prägt einen photographisch genauen Abdruck", apud Assmann, 1999, 157 e 247). Ou seja, a fotografia se tornou na modernidade uma imagem potente para apresentar a nossa paisagem psicológica. Benjamin, por sua vez, era adepto de uma passagem de André Monglond, que ele citou mais de uma 
vez. Com ela vemos que o próprio Benjamin deixou claro que não só podemos, mas devemos aproximar a sua teoria da dialética paralisada e das imagens dialéticas (que são imagens para serem lidas) do dispositivo fotográfico: "Se quisermos conceber a História como um texto, então vale para ela o que um novo autor fala sobre textos literários" (BENJAMIN, 1974, 1238): “O passado deixou dele mesmo, nos textos literários, imagens comparáveis àquelas que a luz imprime sobre uma placa sensível. Apenas 0 porvir possui os reveladores suficientemente ativos para desvendar de modo perfeito tais clichês."' (BENJAMIN, 1982, 603). E o comentário de Benjamin a esse trecho soa como uma profissão de fé que poderia servir de epígrafe à sua obra: "O método histórico é um método filológico, no qual o livro da vida está na base. 'Ler o que nunca foi escrito' é afirmado em Hoffmannsthal. $\mathrm{O}$ leitor no qual deve-se pensar aqui é o verdadeiro historiador" (BENJAMIN, 1974, 1238).

A metáfora fotográfica é tanto mais potente em Benjamin, na media em que crítico e aparelho fotográfico se voltam para o momento da catástrofe da cultura, ou seja, para a "recordação como ela relampeja no momento do perigo." Como ele observa em sua "Pequena história da fotografia": "A câmara se torna cada vez menor, cada vez mais apta a fixar imagens efêmeras e secretas, cujo efeito de choque paralisa o mecanismo associativo do espectador" (BENJAMIN, 1985, 107) e, desse modo, o contamina com o choque. Mas a tarefa do crítico materialista não é só a de fotografar o choque e de interromper o fluxo da narrativa, como Benjamin logo pontua: "Aqui deve intervir a legenda, introduzida pela fotografia para favorecer a liberalização de todas as relações da vida e sem a qual qualquer construção fotográfica corre o risco de permanecer vaga e aproximativa." Também no ensaio sobre a obra de arte, ao tratar das consagradas fotos de Atget das cidades de Paris, Benjamin volta a essa tese. ${ }^{6}$ Essas fotos urbanas, esvaziadas de figuras

\footnotetext{
${ }^{6} \mathrm{Em}$ "O autor como produtor", Benjamin articula essa teoria positiva da legendagem a uma passagem do escritor à atividade de fotógrafo. A foto surge como meio de superação da divisão de trabalho da sociedade burguesa: "Temos que exigir dos fotógrafos a capacidade de colocar em suas imagens legendas explicativas que as liberem da moda e lhes confiram um valor de uso revolucionário. Mas só poderemos formular convincentemente essa exigência quando nós, escritores, começarmos a fotografar. Também aqui, para o autor como produtor o progresso técnico é um fundamento do seu progresso político. Em outros termos: somente a superação daquelas esferas compartimentalizadas de competência no

Professor titular de Teoria Literária do Instituto de Estudos da Linguagem, IEL da

Universidade Estadual de Campinas, UNICAMP. Brasileiro, residente em Campinas - SP. Email: $\underline{\text { m.seligmann@uol.com.br }}$
} 
humanas, surgem, comenta Benjamin, como o local de um crime. As fotos ganham assim o significado de provas, de conjunto de indícios, no processo histórico. Cabe ao crítico da cultura legendar essas imagens, dando a elas seu sentido político. Novamente: a imagem dialética é o fruto do curto circuito do acorrido com o agora e se dá na interação entre o verbal e o imagético. É imagem lida, tanto quanto imagem reinscrita, sendo que a inscrição a libera da esfera do culto e da magia, assim como para Benjamin, ao falar da importância dos sonhos, ele valoriza a sua reapropriação no momento do despertar, e não uma valorização do sonho em si. A fotografia de violência tem a capacidade tanto de gerar um escudo de Perseu para cenas que de outra forma nos paralisariam, como também, de certa forma, acaba por adquirir a capacidade de nos chocar também e marcar por toda vida, como Susan Sontag narra com relação à impressão que as fotos de campos de concentração nazistas deixaram nela quando as contemplou pela primeira vez. O crítico materialista, com a sua legendagem das imagens, rompe o encanto petrificante do choque e permite a elaboração crítica e transformadora do ocorrido.

\section{A segunda técnica}

Para concluir essas reflexões sobre o papel da fotografia no pensamento de Benjamin gostaria de tratar de seu conceito de segunda técnica que anunciei acima. No capítulo VI da segunda versão do texto de Benjamin sobre a obra de arte, ele opõe o valor de culto, ligado ao ritual e à era aurática da recepção das obras de arte, ao valor de exposição, que segundo ele só faria aumentar com a reprodutibilidade técnica. Ele vê um processo que teria ido da pura magia da arte feita nas cavernas (que só posteriormente foi reconhecida como arte) ao fim da arte, que ele vê anunciado na reprodutibilidade técnica e na escalada do valor de exposição. Nesse ponto, Benjamin introduz uma importantíssima reflexão sobre a 
relação entre a arte, a técnica e o jogo. Essa passagem encontra-se apenas na versão francesa e na segunda versão alemã desse ensaio sobre a obra de arte. Na primeira versão do ensaio, Benjamin faz uma teoria da técnica moderna como uma "segunda natureza". Com as guerras e crises econômicas essa segunda natureza necessita também, como a primeira, ser dominada. ${ }^{7}$ O cinema é visto aí, para Benjamin, como um meio de aproximação e domínio dessa técnica transformada em segunda natureza: "Fazer da monstruosa aparelhagem técnica de nossos tempos o objeto da enervação humana - é esta a tarefa histórica em cujo serviço o cinema tem seu verdadeiro sentido." (BENJAMIN, 2013, 102; BENJAMIN, 1974, 445) No cinema, a humanidade poderia também testar novas modalidades de convívio intra-humano e com a natureza e, dessa forma, ensaiar ludicamente - seu futuro.

Na segunda versão, porém, Benjamin fala de uma técnica emancipada que seria uma "segunda técnica". A primeira técnica tinha o ser humano em seu centro e tinha como sua imagem paroxística o próprio sacrifício humano; já a segunda técnica tende a dispensar o ser humano do trabalho. ${ }^{8} \mathrm{~A}$

\footnotetext{
${ }^{7}$ Benjamin conclui a primeira versão do ensaio sobre a obra de arte falando de uma técnica que cobra sacrifícios: "Essa guerra é uma revolta da técnica, que cobra em 'material humano' o que the foi negado pela sociedade" (Benjamin 1985: 196). Também no ensaio de Benjamin sobre o livro Guerra e Guerreiros, de Ernst Jünger, ele tratou da técnica em uma chave negativa: "Cada guerra que se anuncia é ao mesmo tempo uma revolta da técnica." Mas ele escreve na mesma passagem desse texto, de 1930, anunciando uma visão positiva da técnica, "que a realidade social não estava madura para transformar a técnica em seu órgão, e que a técnica não era suficientemente forte para dominar as forças elementares da sociedade." (Benjamin 1985: 61; tradução modificada) O texto conclui falando da necessidade de uma transformação da técnica em "chave para a felicidade". (Benjamin 1985, 72)

${ }^{8}$ Vale lembrar que Benjamin desenvolvera essa dicotomia entre dois tipos de técnica, ainda que de modo não tão explicito e ainda tratando da técnica como uma segunda natureza, em seu último fragmento de Rua de mão única. Nesse texto, denominado de "A caminho do planetário", Benjamin trata do tema caro a ele do abandono, que teria ocorrido na modernidade, da percepção das afinidades eletivas, ou do mundo das semelhanças, que uniam a humanidade, o macro- e o microcosmo. Ele escreve sobre a técnica destrutiva e sacrificial que culminou na primeira guerra e também sobre uma técnica que não seria mais dominação, que ele vê in nuce na força proletária: "Massas humanas, gases, forças elétricas foram lançadas ao campo aberto, correntes de alta frequência atravessaram a paisagem, novos astros ergueram-se no céu, espaço aéreo e profundezas marítimas ferveram de propulsores, e por toda parte cavaram-se poços sacrificiais na Mãe Terra. Essa grande corte feita ao cosmos cumpriu-se pela primeira vez em escala planetária, ou seja, no espírito da técnica. Mas, porque a avidez de lucro da classe dominante pensava resgatar nela sua vontade, a técnica traiu a humanidade e transformou o leito de núpcias em um mar de sangue. Dominação da Natureza, assim ensinam os imperialistas, é o sentido de toda técnica. [...] a técnica não é dominação da Natureza: é dominação da relação entre Natureza Professor titular de Teoria Literária do Instituto de Estudos da Linguagem, IEL da

Universidade Estadual de Campinas, UNICAMP. Brasileiro, residente em Campinas - SP. Email: m.seligmann@uol.com.br
} 
segunda técnica baseia-se na repetição lúdica e teria sua origem no jogo, visto por Benjamin como primeira modalidade de tomada de distância da natureza. ${ }^{9}$ Lembremos também aqui da teoria freudiana do jogo: o "fort-da" (o brincar de desaparecer) do bebê como uma elaboração da separação/realidade (FREUD, 1989, 225s.). Mas para Benjamin essa segunda técnica não visa a um domínio da natureza, mas sim jogar com ela. O jogo aproxima, mas mantém a distância. A primeira técnica seria mais séria e a segunda lúdica: a obra de arte estaria no meio, oscilando entre a primeira e a segunda técnicas. O cinema e a fotografia, por serem artes eminentemente dependentes da técnica, estariam mais próximas dessa segunda técnica e atuariam justamente no treino em direção a essa segunda técnica emancipadora. Em uma importante nota de rodapé, que não consta nas demais versões alemãs do ensaio senão na segunda, Benjamin trata da relação dessa segunda técnica com as revoluções e utopias. Aqui ele apresenta o conceito fundamental de Spielraum, campo de ação, mas também, espaço de jogo: “Justamente porque essa segunda técnica pretende liberar progressivamente o ser humano do trabalho forçado, o indivíduo vê, de outro lado, seu campo de ação aumentar de uma vez para além de todas as proporções." (BENJAMIN, 2013, 63; BENJAMIN, 1989a, 360) Benjamin

e humanidade. Os homens como espécie estão, decerto, há milênios, no fim de sua evolução; mas a humanidade como espécie está no começo. Para ela organiza-se na técnica uma physis na qual seu contato com o cosmos se forma de modo novo e diferente do que em povos e famílias." (BENJAMIN, 1987, 69) Cf. Também uma passagem semelhante sobre o caráter emancipado da técnica no comunismo em BENJAMIN, 1987, 187 (“Moscou").

Nesse sentido, é fundamental ler um fragmento das notas de Benjamin para entender essa relação entre o jogo, a segunda técnica e a articulação com a teoria da experiência (que Benjamin desenvolvia na mesma época de seu trabalho sobre a obra de arte, no seu ensaio sobre a narração, "O narrador", de 1936): "A primeira técnica excluía a experiência do indivíduo. Toda experiência mágica da natureza era coletiva. A primeira abordagem de uma experiência individual aconteceu no jogo [Spiel]. Dela desenvolveu-se então a científica. As primeiras experiências científicas ocorrem sob a proteção do jogo descompromissado. Essa experiência é aquela que, em um processo que dura milênios, leva à desaparição da representação e talvez também da realidade daquela natureza que correspondia à primeira técnica." (BENJAMIN, 1974, 1048) Benjamin desenvolveu sua teoria e sociologia do jogo tanto nos fragmentos escritos no contexto do seu trabalho sobre as passagens de Paris, como nos ensaios sobre Baudelaire diretamente ligados a esses fragmentos e nos seus textos sobre jogos infantis e o brincar. $O$ jogo é visto tanto como uma contraparte do trabalho alienado, como um meio de ir contra ele, já que no jogo existe um deslocamento da esfera da produção para a lúdica (ainda que o "ganhar" seja o decisivo em ambas esferas). Em Parque central Benjamin anotou: "Os jogos de azar, o flanar, o colecionar - atividades que se contrapõem ao spleen." (BENJAMIN, 1989, 161) Tanto o jogo, como o flanar e o colecionar seriam gestos que guardam algo de revolucionário, para Benjamin.

Professor titular de Teoria Literária do Instituto de Estudos da Linguagem, IEL da Universidade Estadual de Campinas, UNICAMP. Brasileiro, residente em Campinas - SP. Email: m.seligmann@uol.com.br 
afirma também que diante dessa segunda técnica "as questões vitais do indivíduo - amor e morte - já exigem novas soluções". (BENJAMIN, 2013, 63; BENJAMIN, 1989a, 360) Essa ideia ainda parece constar como mote para as obras de arte produzidas em nossa era, e isso vale não apenas com relação às ficções científicas. Boa parte das obras de arte hoje explora esses novos espaços de jogo e de liberdade que a técnica nos abre. São incursões sobre o novo sentido da vida - e da biopolítica - na era da síntese técnica da vida. Elas colocam questões a nós humanos, habitantes da era da crise das fronteiras (geográficas, biológicas e outras mais), da mobilidade incessante, da ansiedade, do fim do trabalho - esse definidor de nossa humanidade por tantos séculos. Para Benjamin, mais do que a fotografia, sobretudo o cinema já trazia em si a semente de uma era pós divisão de trabalho, uma vez que nele trabalho intelectual e manual têm a sua diferença liquidada. Com essa liquidação também se permite vislumbrar no cinema o que Benjamin denomina de "formação politécnica da humanidade". 10 Ou seja, diferentemente da maioria dos críticos da sociedade, Benjamin procura manter nesse ensaio uma visão positiva dos avanços da técnica. $\mathrm{Na} 11^{\mathrm{a}}$ das teses "Sobre o conceito de história" ele desenvolve uma crítica do conceito utilitarista de trabalho da social-democracia de Josef Dietzgen, que veria no trabalho apenas um meio de conquista e submissão da natureza: "Já estão visíveis, nessa concepção, os traços tecnocráticos que mais tarde vão aflorar no fascismo." (BENJAMIN, 1985, 228) Benjamin em seguida contrapõe essa visão instrumental da natureza com a de Fourier, que via na técnica um modo

\footnotetext{
${ }^{10}$ BENJAMIN, 1974, 1051. Nas notas preparatórias a essa passagem da segunda versão do ensaio sobre a obra de arte, que trata dos novos desafios diante do "amor e morte" (a última nota do capítulo VII), Benjamin elabora essa relação entre utopia, técnica e revolução do ponto de vista de uma teoria da primeira e da segunda naturezas (e não da primeira e segunda técnicas). É interessante comparar essas duas passagens para tentar entender como Benjamin pensou essas duas teorias (a da primeira e segunda natureza e a da primeira e segunda técnica). Benjamin escreve que os problemas da segunda natureza logo estarão resolvidos e que restará somente resolver os da primeira natureza, "o amor e a morte", ou seja, os temas da zoe, a natureza primária, amorfa. (BENJAMIN, 1989a, 665s. Cf. Também o fragmento mais curto com um teor semelhante em Benjamin, 1974, 1045.) Em outro fragmento da mesma época ele anota essa passagem fundamental: "Pois não é apenas a segunda natureza, da qual o coletivo se apropria como a sua primeira [natureza] na técnica, que coloca as suas reivindicações revolucionárias. Também a primeira natureza, a orgânica e em primeiro lugar a do organismo corporal [leiblich] do indivíduo, de longe ainda não se tornou sua." (BENJAMIN, 1989a, 666) A técnica, como natureza de segunda ordem, corresponderia à natureza da coletividade. Nem ela, nem a primeira natureza foram ainda devidamente conquistadas.

Professor titular de Teoria Literária do Instituto de Estudos da Linguagem, IEL da Universidade Estadual de Campinas, UNICAMP. Brasileiro, residente em Campinas - SP. Email: m.seligmann@uol.com.br
} 
de extrair da natureza a sua força adormecida: de transformá-la plasticamente, construindo uma utopia, desabrochando na natureza a mesma plasticidade que se vê nos desenhos animados de Mickey, que Benjamin tanto admirava: "O trabalho, como a partir de então [1848] é compreendido, visa uma exploração da natureza, a qual é contraposta, com ingênua complacência, à exploração do proletariado. Comparadas a essa concepção positivista, as fantasias de um Fourier, tão ridicularizadas, revelam-se surpreendentemente razoáveis. Segundo Fourier, o trabalho social bem organizado teria entre seus efeitos que quatro luas iluminariam a noite, que 0 gelo se retiraria dos polos, que a água marinha deixaria de ser salgada e que os animais predatórios entrariam a serviço dos seres humanos. Essas fantasias ilustram um tipo de trabalho que, longe de explorar a natureza, é capaz de liberar as criações que dormitam, como possibilidades, em seu ventre. Ao conceito corrompido de trabalho corresponde, como seu complemento, aquela natureza que, segundo Dietzgen, 'está aí, grátis'." (BENJAMIN, 1985, 228, tradução modificada) ${ }^{11}$

Segundo Benjamin "na mimese dormitam, dobradas estreitamente uma sobre a outra, como os cotilédones de um broto, os dois lados da arte: aparência e jogo [Schein und Spiel]". (BENJAMIN, 2013, 74; BENJAMIN, 1989a, 368) Para ele no cinema - que desdobra de modo potencializado as energias da fotografia - a "natureza ilusória é uma natureza de segundo grau" (BENJAMIN, 2013, 80; BENJAMIN, 1989a, 373), obtida por meio do corte. A realidade livre dos aparelhos aparece agora, segundo Benjamin, apenas por meio do próprio aparelho. Daí ele fazer sua famosa - e mal compreendida - afirmação: "a visão da efetividade imediata tornou-se a flor azul no país da técnica". (BENJAMIN, 2013, 80; BENJAMIN, 1989a, 373) A flor azul é uma metáfora romântica para a totalidade, o absoluto como fusão com a natureza, fim da tristeza do estar no mundo. Novalis, no romance intitulado Heinrich von Ofterdingen - que ele deixou em forma de fragmento, quando de sua morte em 1801, apenas com 29 anos de idade - apresenta a

\footnotetext{
${ }^{11}$ Essa teoria da segunda técnica, ainda que sem a utilização desses termos, foi desenvolvida de modo cabal pelos últimos textos de Vilém Flusser, sobretudo em seu livro de 1985, O universo das imagens técnicas.
}

Professor titular de Teoria Literária do Instituto de Estudos da Linguagem, IEL da Universidade Estadual de Campinas, UNICAMP. Brasileiro, residente em Campinas - SP. 
imagem da flor azul (Blaue Blume) de modo extremamente significativo. Esse romance contém em sua cena inicial uma espécie de devaneio que leva Heinrich ao mundo da flor azul. Nesse estado, ele pensa consigo: "O que despertou em mim uma ânsia inominável não são os tesouros; estou longe de toda cobiça: mas eu desejo vislumbrar a flor azul. Ela permanece o tempo todo em meu pensamento e eu não posso poetar ou pensar em outra coisa." Nesse estado, o protagonista entra em um mundo onírico que o faz lembrar de um passado no qual "animais e árvores e rochas conversavam com os homens." Benjamin traduz esse sonho romântico para a era das imagens técnicas: nela, a flor azul nasce do aparelho. Não há mais mimese da natureza como aparência, mas, antes, mimese como jogo: trata-se de um jogar junto com a natureza, atuar com ela. O bisturi, que Benjamin compara à câmera, penetra na realidade, mais fundo do que a pintura, que ficava apenas no âmbito da (bela) aparência, como um curandeiro, que não toca seus pacientes (mantendo a distância "aurática"). A segunda técnica, por outro lado, nos traz o real. Essa ideia, de resto, já se encontrava in nuce no mencionado ensaio de Baudelaire, que via criticamente na fotografia um meio de apropriação do real sem retoques. Benjamin aprofundou essa tese de modo positivo. Hoje, na era dos pixels e das imagens eletrônicas, vemos esse fenômeno da flor azul como fruto da técnica intensificar-se. O mundo onde humanos e a natureza falam pode ser visto no cinema, de um modo bem distinto como aparecia no sonho de Heinrich von Ofterdingen. Resta também saber, como na época de Benjamin, que tipo de frutos teremos a partir dessas flores. Cabe a nós atuar no sentido de tornar esses frutos emancipadores e não fascistas.

\section{REFERÊNCIAS}

ASSMANN, Aleida. Erinnerungsräume. Formen und Wandlungen des kulturellen Gedächtnisses. München: C.H. Beck, 1999.

BENJAMIN, Walter. Passagens. org. W. Bolle e O. Matos, tradução Cleonice Paes Barreto Mourão e Irene Aron, São Paulo: Editora UFMG e Imprensa Oficial do Estado de São Paulo, 2006.

Professor titular de Teoria Literária do Instituto de Estudos da Linguagem, IEL da Universidade Estadual de Campinas, UNICAMP. Brasileiro, residente em Campinas - SP. 
Gesammelte Schriften, vol. III: Kritiken und Rezensionen. Org. por R. Tiedemann und H. Schweppenhäuser, Frankfurt a.M.: Suhrkamp, 1972.

1974.

Gesammelte Schriften. Frankfurt a.M.: Suhkamp, vol. I, . Gesammelte Schriften, vol. V: Das Passagen-Werk, 1982.

Obras escolhidas, v. I, Magia e técnica, arte e política. Trad. S.P. Rouanet. São Paulo: Brasiliense, 1985.

Obras escolhidas, v. II, Rua de mão única. Trad. de R.R. Torres F. e J.C.M. Barbosa, São Paulo: Brasiliense, 1987.

Obras escolhidas, v. III, Charles Baudelaire, um lírico no auge do capitalismo. Trad. de J.C.M. Barbosa e H.A. Baptista, São Paulo: Brasiliense, 1989.

Gesammelte Schriften, vol. VII: Nachträge, 1989a.

Das Kunstwerk im Zeitalter seiner technischen Reproduzierbarkeit. Comentado por Detlev Schöttker, Frankfurt a.M.: Suhrkamp, 2007.

A obra de arte na era da sua reprodutibilidade técnica. Trad. Gabriel Valladão Silva, revisão técnica Márcio SeligmannSilva, 2013.

ENTLER, Ronaldo. "Retrato de uma face velada: Baudelaire e a fotografia", in: FACOM, no. 17, 2007, pp. 4-14.

FREUD, Sigmund. O mal-estar na cultura. Tradução de Renato Zwick, revisão técnica de M. Seligmann-Silva, Porto Alegre: L\&PM, 2010.

. Jenseits des Lustprinzips, in: Studienausgabe. Vol. III, Frankfurt am Main: Fischer, 1989, pp. 213-272.

LESSING, G.E. Laocoonte. Ou sobre as Fronteiras da Poesia e da Pintura. Tradução M. Seligmann-Silva, São Paulo: lluminuras, Segunda edição, revisada e ampliada, 2011.

MOHOLY-NAGY. "Diskussion über Ernst Kállai's Artikel 'Malerei und Fotografie"' ["Discussão sobre o artigo de Ernst Kállai 'Pintura e fotografia'"], in: Moholy-Nagy, László Moholy-Nagy. Kassel: Weber \& Weidmeyer, 1991.

WINCKELMANN, Johann Joachim. Von der Nachahmung der griechischen Werke in der Malerei und Bildhauerkunst, in: Winckelmann, Anton Raphael 
Mengs e Wilhelm Heinse, Frühklassizismus, org. por Helmut Pfotenhauer et alii, Frankfurt a.M.: Deutsche Klassiker Verlag, 1995. 